\title{
Tributación presuntiva para el desarrollo sostenido y equitativo
}

\author{
El logro del desarrollo sostenido y equitativo es \\ el desafio más grande que enfrenta la raza humana. \\ World Development Report 1992.
}

\section{Introducción}

Los impuestos sobre la renta y sobre el valor agregado (IVA) ya son los dos impuestos principales de El Salvador. En 1996 estos impuestos rindieron casi 80 por ciento de los ingresos tributarios totales (Banco Central de Reserva, datos). Los ingresos de ambos impuestos han aumentado con el tiempo, pero los ingresos del IVA han aumentado mucho más rápidamente que los del impuesto sobre la renta. Entre 1989 y 1996, los ingresos del impuesto sobre la renta aumentaron 370 por ciento, de 581.4 millones hasta $2,732.5$ millones de colones. Durante el mismo período, los ingresos del impuesto sobre la venta (Timbres Fiscales/IVA) aumentaron 595 por ciento, de 764.0 millones a 5,310.3 millones de colones. Los ingresos del IVA ya son casi el doble de los del impuesto sobre la renta.

El impacto más perjudicial de esta tendencia es el atraso en el logro de un desarrollo sostenido y equitativo. El IVA es un impuesto regresivo (las familias de pocos recursos pagan una proporción relativamente alta de su renta en forma de impuesto), mientras que el impuesto sobre la renta es progresivo (McGuire, pp. 645-47, 653, 659-661). Por esto, el aumento relativamente rápido del IVA hace al sistema tributario más regresivo de lo que sería si se hiciera más énfasis al impuesto sobre la renta.

La tributación regresiva alrasa la satisfacción de las necesidades básicas que generan una fuerza de trabajo capaz de contribuir al desarrollo del país según su polencial. Para ilustrar, la familia de pocos recursos que sufre la tributación regresiva es menos capaz de pagar los coslos directos de la educación, así como 
el "costo de oportunidad" de perder el trabajo, de los niños mientras estudien. Algunos niños comen menos. Otros nunca se matriculan. Así, la educación de los niños y su incorporación en el proceso de desarrollo se atrasa. Aunque el gobierno utilice sus ingresos tributarios regresivos para construir una escuela nueva, lo hace quitándoles a los niños menos capaces de aprender. El gobierno da con la mano derecha, pero toma con la mano izquierda. Se podría evitar tal política contradictoria con el uso del impuesto progresivo sobre la renta para recaudar fondos, y usando los fondos para satisfacer las necesidades básicas.

La mejor razón para no enfatizar el impuesto sobre la renta ha sido lécnica. Es técnicamente difícil imponer un impuesto sobre la renta de ciertos grupos, entre los cuales los más importantes son las empresas pequeñas y medianas, los profesionales y los agricultores. En estos casos, grandes cantidades de contribuyentes resultan en allos coslos administrativos que fácilmente superan los ingresos tributarios. Además, eslos contribuyentes con frecuencia no pueden, o no quieren, mantener los libros de comercio. Otros sí los mantienen, pero los oficiales tienen poca evidencia por la que pueden juzgar su exaclitud.

Como resultado, el impuesto sobre la renta que teóricamente es "el mejor de todos los impuestos", degenera en la práctica en un impuesto pagado principalmente por un número reducido de trabajadores del sector formal y por las empresas grandes. Esto causa una pérdida de ingresos tributarios para el gobierno, que le hace más dificil salisfacer sus obligaciones financieras. También se crea una competencia desleal entre las empresas que sí pagan el impuesto y las que no lo pagan. Igualmente, la inequidad horizontal resulta entre las personas que pagan el impuesto y las que no lo pagan. La reacción natural es reducir el énfasis en el impuesto sobre la renta y depender más del impuesto del IVA.

El propósito de este arlículo es bosquejar un método factible y eficaz que permita superar las dificultades técnicas para imponer un impuesto progresivo sobre la renta. La metodología se llama "tribulación presuntiva." La meta final es lograr un desarrollo sostenido para todos.

La Parte I bosqueja un modelo de tributación presuntiva que le fue recomendado a Bolivia en 1977 por el renombrado economista Richard Musgrave (Musgrave, cap. 17-18). La Parte II reflexiona sobre la experiencia salvadoreña con la tributación presuntiva a la luz del modelo. La Parte III describe el movimiento corriente para efectuar la tributación presuntiva por toda Latinoamérica. El trabajo concluye con algunas sugerencias para la política.

\section{El modelo de tributación presuntiva tres Grupos}

El impuesto sobre la renta presunta comienza por distinguir tres gnupos de contribuyentes, empresas "muy pequeñas," las "pequeñas" y las "otras". Los criterios que definen el límite bajo de los contribuyentes "pequeños" incluyen: (1) 
una renta que supera la renta mínima sujeta legalmente al impuesto $(22,000$ colones), y (2) los ingresos tributarios recaudados que exceden los costos de administración. Los criterios que definen el límite superior incluyen: (1) el contribuyente debe tener la capacidad de mantener libros de comercio, y (2) el aumento de los ingresos tributarios deben exceder los costos adicionales de administración. Los contribuyentes "muy pequeños" caen debajo del límite inferior de los contribuyentes "pequeños". Los "otros" contribuyentes caen arriba del límile superior de los contribuyentes "pequeños".

Las empresas "muy pequeñas" están exentas del impuesto sobre la renta. El modelo presenta dos métodos distintos de tributar para las empresas "pequeñas" y las "otras". Las dos partes que siguen presentan estos mélodos.

\subsection{Empresas pequeñas}

El Cuadro 1 ilustra el método que utilizan las empresas pequeñas para tributar. La primera columna y la primera fila muestran que el primer paso es clasificar las empresas según dos criterios: el tipo de negocio y las ventas brutas.

Las cifras del cuadro indican el impuesto vencido por todas las empresas que caen dentro de cualquier categoría. Los niveles del impuesto son establecidos para que igualen aproximadamente las obligaciones que resultarían si el impuesto regular sobre la empresa, el impuesto sobre la renta personal y el IVA fueran cobrados simultáneamente. Los impuestos son fijados a niveles conservadores para reducir la posibilidad de una adversidad excesiva en casos particulares, y para minimizar protestas. Los distintos niveles del impuesto reflejan el hecho de que la razón entre la renta y las ventas varía sustancialmente entre actividades. El símbolo "S.R." indica el nivel de ventas en que comienza el "sistema regular" de tribulación.

Se exige que cada contribuyente registre una declaración corta que proporcione la información necesaria para una clasificación correcta. La declaración incluye una identificación del contribuyente, una descripción de la empresa y un estimado de las ventas brutas. Se exige que el contribuyente mantenga libros simples de comercio para que puedan hacer la declaración. Tanto el mantener los libros como el registrar una declaración ayudan a llevar al contribuyente hacia el sistema regular de tributación.

El cuadro está construido por una unidad especial creada en el Ministerio de Hacienda. Esta unidad está compuesta principalmente de economistas que trabajan en asociación estrecha con los oficiales de tributación y las asociaciones de comercio. La unidad puede comenzar la clasificación de las empresas pequeñas utilizando los códigos de la Standard Industrial Classification (SIC). La unidad, entonces, utiliza muestras para estimar las ventas promedios, la ganancia y el 


\section{Cuadro 1}

Impuesto presuntivo pagable por contribuyentes pequeños

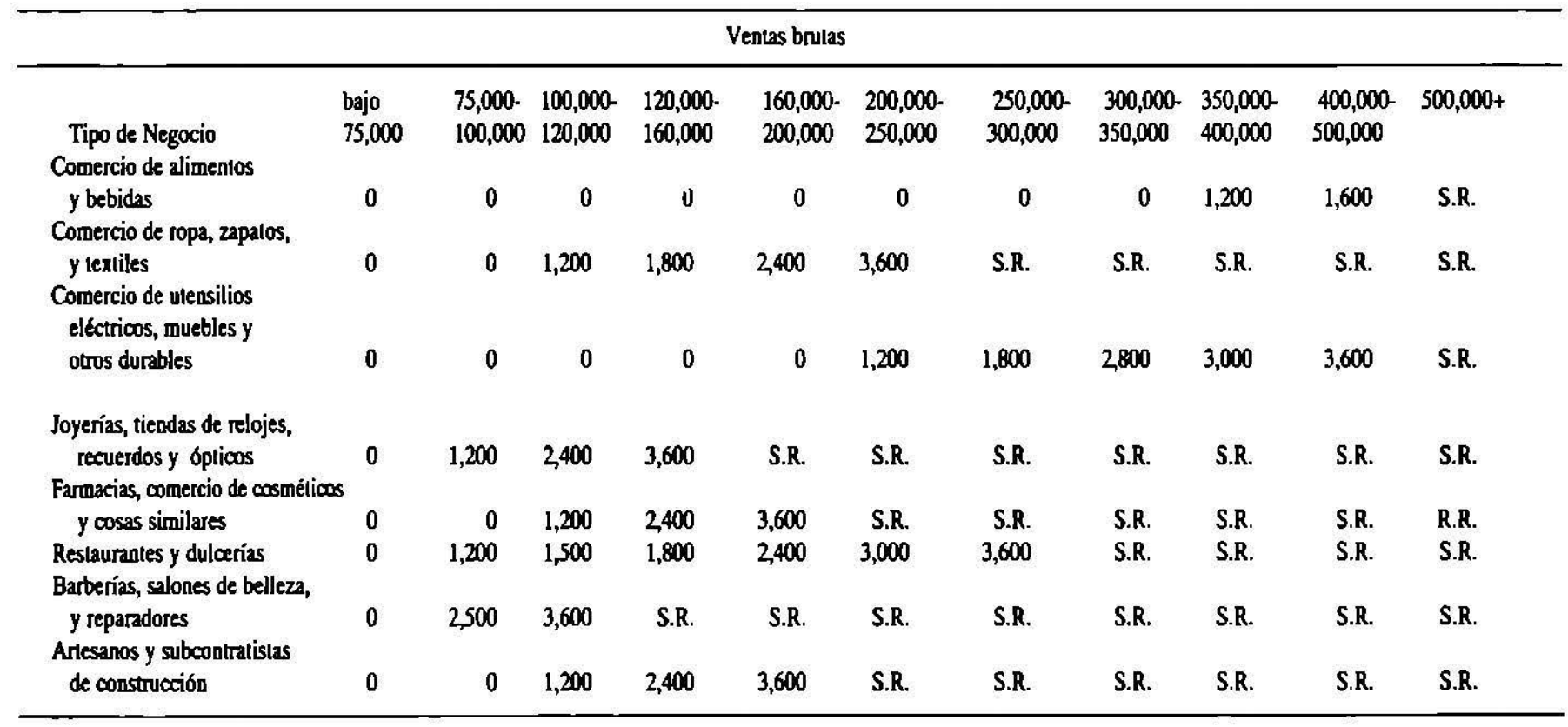

Clave: S.R. = Sistema Regular 
impuesto debido para cada clase de negocio. Más adelante se tratará con más detalle esta unidad especial del Ministerio de Hacienda.

La elaboración del cuadro no es muy difícil. La dificultad más grande se encuentra en clasificar a los contribuyentes individuales por nivel de ventas. ¿Cuáles son las ventas actuales de la empresa $B$ ? Se exije un informe de ventas en la declaración corta, pero el nivel reportado no es confiable. Por lo tanto, se usan indicadores indireclos para hacer los estimados confiables de ventas. El uso de estos indicadores se ilustra en las secciones que siguen.

Se puede cuestionar: ¿Por qué tributar a las empresas pequeñas? La hipótesis es que todos los contribuyentes que deben ser eximidos del impuesto sobre la renta son, de hecho, eximidos por la ley que establece el nivel mínimo de renta sujeta al impuesto; si no, se debe elevar el nivel de la exención. Además, la ley debe establecer una progresividad de tasas tributarias propias comenzando con una tasa suficientemente baja. Después de diseñar un sistema bueno, la mejor manera de promover el desarrollo es aplicarlo a todos los contribuyentes designados y usar los ingresos tributarios para satisfacer las necesidades básicas, etc. Por otro lado, es necesario introducir la tributación de la renta presunta en etapas. Más adelante se verá que los oficiales deben enfocarse en los contribuyentes pequeños en la última etapa.

\subsection{Profesionales: abogados}

El principal segundo grupo consiste en "otros" contribuyentes. El modelo exige que los miembros de este grupo participen del sistema regular de tributación: que mantengan libros de comercio, registren declaraciones de rentas y paguen impuestos basados en esas declaraciones. Sin embargo, dentro de este grupo se encuentran tres categorías de contribuyentes que son "difíciles de tributar". Estos contribuyentes están en las clases media y alta y son capaces de participar en el sistema regular de tributación, pero tienen una historia de cumplimiento bajo. Los miembros más importantes de esta categoría son los profesionales, los agricultores y las empresas medianas. Vamos a analizar a estos contribuyentes por separado.

El diccionario define a los profesionales como "personas que tienen una vocación que exige educación extendida". Los profesionales incluyen abogados, ingenieros, médicos, contadores, dentistas, arquitectos y otros. El profesor Musgrave encontró evidencia que sugirió bastante evasión de los profesionales bolivianos. La metodología que sigue constituye un método para estimar independiente y objetivamente la renta imponible de los profesionales individuales. Estos estimados se usan para verificar sus declaraciones y ajustar su pago.

Esta metodología difiere de la que se usa para los contribuyentes pequeños. En ese caso, no se estima el impuesto debido por cada contribuyente. En lugar de ello se estima un solo impuesto debido por todos los miembros de una categoría. 
El Cuadro 2 ilustra el método para estimar indirectamente las obligaciones tributarias de un tipo de profesional, los abogados. La Parte I identifica una serie de indicadores indirectos que se usan para estimar la renta bruta. El cuadro muestra que, en promedio, los graduados comienzan la práctica de derecho con una renta básica de \$b 120,000 . Sus rentas aumentan por ciertos porcentajes según los indicadores indirectos enlistados en la columna primera.

\section{Cuadro 2}

Modelo de indicadores indirectos para la profesión legal

\begin{tabular}{|c|c|}
\hline \multicolumn{2}{|l|}{ I. Renta bruta } \\
\hline Factores que determinan la renta & $\begin{array}{l}\text { Renta básica más } \\
\text { tasas adicionales }\end{array}$ \\
\hline $\begin{array}{l}\text { Renta básica, años } 1-3 \text { después de graduación } \\
\text { Adición por cada secretaria } \\
\text { Adición por cada mensajero" } \\
\text { Adición por cada abogado asistente } \\
\text { Años 1-2 en la profesión } \\
\text { Años 3-5 en la profesión } \\
\text { Más de } 5 \text { años' } \\
\text { Adición por ubicación, tamaño y tipo de oficina } \\
\text { superior a la mínima } \\
\text { Adición para los años 3-5 de la práctica } \\
\text { Adición por cada año entre el año quinto } \\
\text { y décimo } \\
\text { Adición por clientes permanentes } \\
80 \% \text { clientes permanentes } \\
50 \% \text { clientes permanentes } \\
25 \% \text { clientes permanentes } \\
5 \% \text { o menos clientes permanentes }\end{array}$ & $\begin{array}{c}\text { \$b } 120,000 \\
20 \% \\
15 \% \\
80 \% \\
100 \% \\
150 \% \\
10-100 \% \\
20 \% \text { cada año } \\
10 \% \text { cada año } \\
300-400 \% \text { } \\
200-250 \% \%^{\mathrm{b}} \\
100-150 \%^{\mathrm{b}} \\
-\end{array}$ \\
\hline
\end{tabular}

\section{Gastos}

(1) No contables

Para una Renla Bruta de

$\$ b 120,000$ - \$b 200,000

\$b 200,000 - \$b 400,000

\$b 400,001 y más

Tasa de

gaslos no contables

$2 \%$

$1 \%$

$\$ b 6,000$ una vez

(2) Contables

Se pueden deducir otros gastos de la renta bruta solamente si son verificados por documentos.

- Si se trabaja menos de tiempo completo, se reduce proporcionalmente.

- Depende del tamaño de la empresa. 
La Parte II especifica los gastos que se pueden sustraer de la renta bruta para llegar a la renta imponible. Se permite una deducción de los gastos "no contables" que iguala los porcentajes estipulados de la renta bruta'. Se pueden deducir los gastos contables solamente si son documentados plenamente.

Los indicadores indirectos son desarrollados por la unidad especial del Ministerio de Hacienda que estudia una muestra de los abogados. Es necesario desarrollar un juego distinto de indicadores para cada categoría de profesionales.

EL Cuadro 3 aplica los criterios para estimar la renta bruta de un abogado para el año 1976. El abogado tiene nueve años de experiencia, emplea dos secretarias, un mensajero y un abogado ayudante que tiene dos años de experiencia. Su oficina está ubicada en el centro y está equipada con muebles modernos. Ochenta por ciento de sus clientes son permanentes y son empresas grandes. Utilizando los indicadores del Cuadro 2, se estima que su renta bruta iguala $\$ b 870,000$.

\section{Cuadro 3}

\section{Ejemplo para el año tributario 1976}

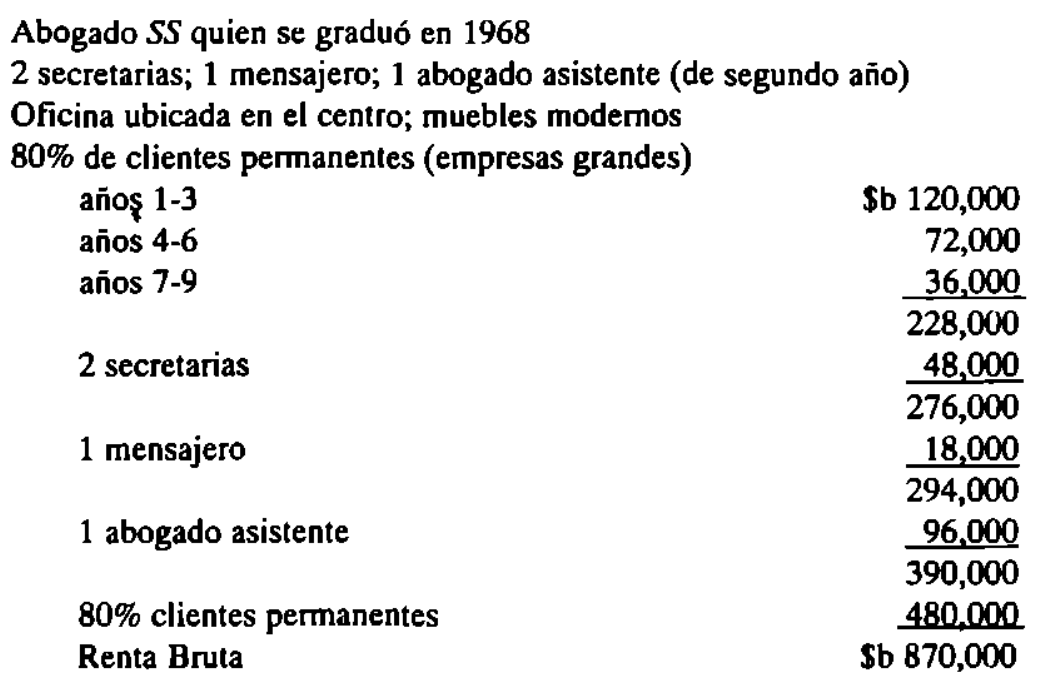

De esta renta bruta se deducen los gastos no contables y los gastos contables que están plenamente documentados. A esta cifra se añade la renta neta ganada en otras actividades. Por fin se usan las tablas tributarias para estimar el impuesto debido por el abogado. Si el impuesto presunto excede el impuesto declarado, se exige que el abogado pague el monto mayor. Se permite refulación solamente 
si es sostenida por documentación completa. Esto empuja a los abogados hacia la participación plena en el sistema regular de tributación sobre la renta.

\subsection{Agricultores}

Usualmente los agricultores contribuyen poco en los ingresos del impuesto sobre la renta (T6́chez). Sin embargo, una proporción significativa del Producto Interno Bruto - 13 por ciento en 1996 - es producido por el sector agrícola (Banco Central de Reserva, p. 85), y en 1991 aproximadamente el 23 por ciento de la fuerza laboral civil fue empleada en el seclor agrícola (National Trade Data Bank). En forma tradicional, algunos salvadoreños más ricos poseen empresas en el sector. Por lo tanto, parece que se podrían - y que se deberíarecoger muchos más ingresos tributarios por un impuesto sobre la renta del sector.

La recomendación es imponer un impuesto sobre la tierra que refleje la renta que se presume obtenible del mejor uso de la tierra. Este método efectúa un impuesto progresivo sobre la renta del sector agrícola y también anima a usar la tierra eficientemente (para que se pueda pagar el impuesto). El Cuadro 4 ilustra la aplicación de la metodología.

\section{Cuadro 4 \\ Tasas del impuesto sobre la tierra basadas en la renta estimada por parcela}

\begin{tabular}{|c|c|c|c|}
\hline \multirow[b]{2}{*}{ Región } & \multicolumn{3}{|c|}{ Impuesto por hectárea cultivable ${ }^{*}$} \\
\hline & $\begin{array}{c}\text { Tenencia } \\
\text { pequeña } \\
(4 \% \text { de renta) }\end{array}$ & $\begin{array}{c}\text { Tenencia } \\
\text { media } \\
\text { (10\% de renta) }\end{array}$ & $\begin{array}{c}\text { Tenencia } \\
\text { grande } \\
\text { (15\% de renta) }\end{array}$ \\
\hline Altiplano del sur (cerca del lago Poopó) & \$b 14 & \$b 35 & Sb 52 \\
\hline Subzona central (cerca del lago Poopó) & 31 & 78 & - \\
\hline Subzona norte (cerca del lagoTiticaca) & 48 & 120 & 一 \\
\hline Subzona Ribereña del norte (lago Titicaca) & 48 & 120 & 180 \\
\hline Subzona Volles Cerrados - General & 60 & 50 & 225 \\
\hline Subzona Valles Abiertos - General & 37 & 68 & 102 \\
\hline Subzona Cabecera de Valles & 23 & 57 & 一 \\
\hline Subzona Yungas & 48 & 120 & 180 \\
\hline Subzona Santa Cruz & 96 & 240 & 360 \\
\hline Subzona Chaco & 60 & 150 & 225 \\
\hline Subzona agrícola tropical & & & \\
\hline (El Beni, Pando, Iturralde) & - & 150 & - \\
\hline
\end{tabular}

- Las tasas son promedios; las tasas actuales dependen de la subzona y del tipo de siembra. 
La primera columna distingue las principales regiones agrícolas del país según la fertilidad de la tierra. La primera fila distingue varios tamaños de tenencia y tasas progresivas del impuesto sobre la renta potencial de las tenencias. El supuesto operante es que la renta (y la capacidad de pagar) varía con la productividad de la tierra y el tamaño de la tenencia. Las cifras dentro de la tabla especifican el impuesto debido por hectárea cultivable y por cada categoría de tierra. Los impuestos fueron estimados al aplicar el impuesto sobre la renta de personas jurídicas y el de la renta de personas naturales a la renta presunta de cada terrateniente.

Se deben tomar en cuenta las circunstancias especiales que causan que la renta actual de una región particular, o de una parcela particular, caiga sustancialmente debajo del nivel presunto. Al contribuyente se le debe dar un formulario especial para reclamaciones de adversidades severas, las cuales deben tratarse pronto. Es necesario documentar plenamente cualquier desviación de la norma.

\subsection{Empresas medianas: restaurantes}

El Cuadro 5 da un bosquejo incompleto que ilustra la tributación presuntiva de un tipo de empresa mediana, restaurantes en La Paz, Bolivia. En las filas de la 1 a la 6 aparecen unas listas de las características que distinguen ocho tipos de restaurantes. La fila 7 enlista un indicador indirecto que se relaciona con las ventas de los restaurantes - la cantidad de mozos. Aquí, el nivel de ventas se relaciona con un solo indicador, pero en un caso real se usarían varios indicadores. La fila 8 muestra el porcentaje de las ventas brutas que se permite deducir por gastos no contables.

El Cuadro 6 determina el impuesto mínimo debido por un restaurante particular de La Paz. La Parte I da una descripción del restaurante e indica que el restaurante pertenece a la categoría cinco del Cuadro 5. La descripción está incluida en la declaración de la renta del restaurante.

La Parte II estima la renta neta. Primero se usa el Cuadro 5 para estimar las ventas brutas y la renta bruta. Luego, se deducen los costos no contables y los contables que han sido plenamente documentados para encontrar la renta neta.

La Parte III aplica las tasas del impuesto sobre la renta de personas jurídicas para estimar el impuesto mínimo debido, \$b 199,200. Se ve que el impuesto mínimo es sustancialmente mayor que el impuesto actualmente pagado, \$b 13,573.

La renta que queda después de pagar este impuesto se añade a la otra renta del dueño para determinar su renta global sujeta al impuesto sobre la renta personal. Una refutación del impuesto estimado se permite solamente si el contribuyente puede documentarla plenamente. 
Cuadro 5

Bosquejo de indicadores indirectos para restaurantes de $\mathbf{L} \mathbf{a} \mathbf{P a z}$

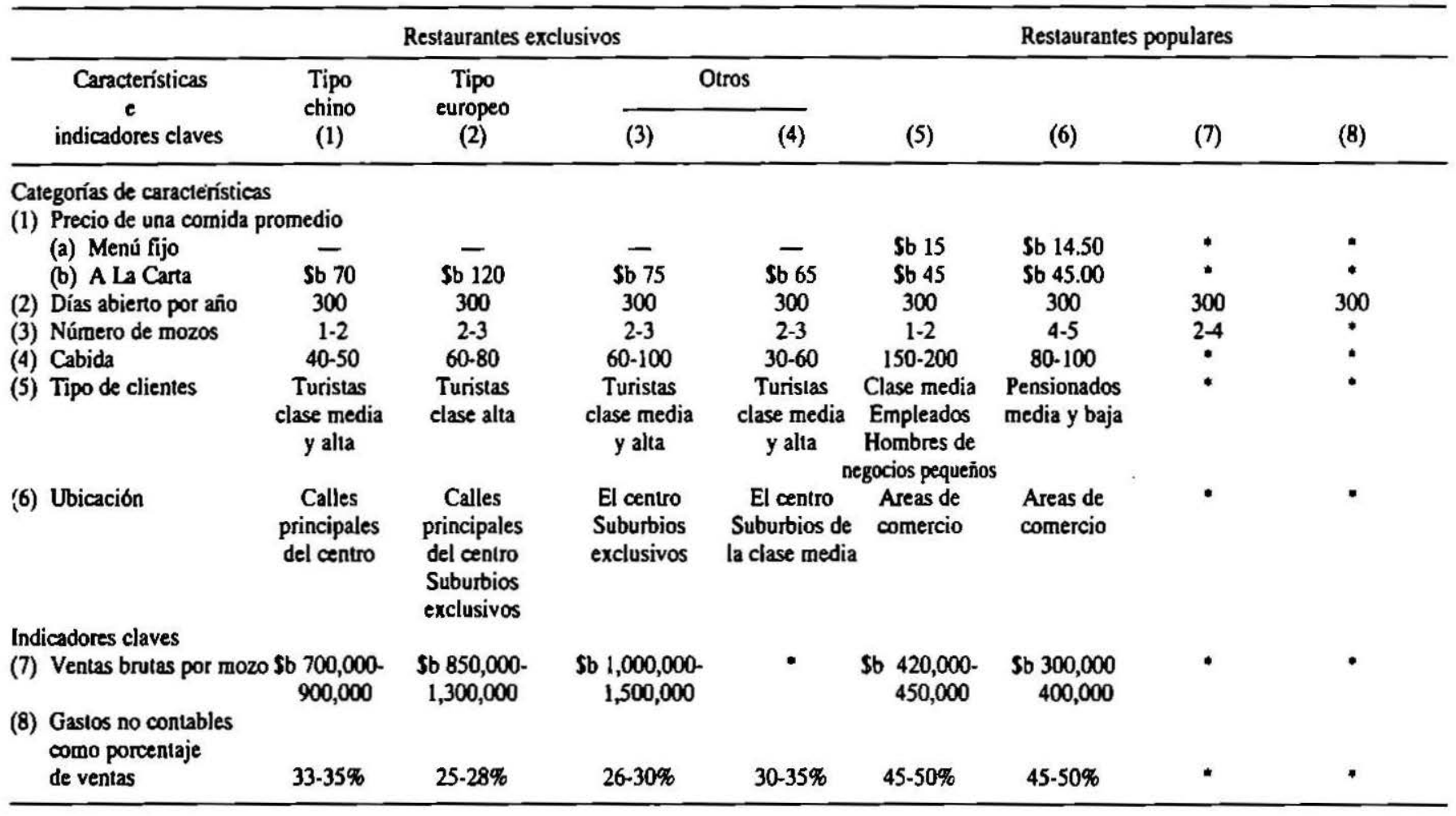

- No determinado. 


\section{Cuadro 6 \\ Reslaurante XX (un caso real)}

\section{Descripción}

\begin{tabular}{|c|c|}
\hline $\begin{array}{r}\text { Ubicación: } \\
\text { Tipo de comida: } \\
\text { Número de mozos: } \\
\text { Otro personal: } \\
\text { Precios: } \\
\text { Horas principales: } \\
\text { Servicios: }\end{array}$ & $\begin{array}{l}\text { Arca de comercio aclivo } \\
\text { Local } \\
\text { Cinco } \\
\text { Diez y siete } \\
\text { Almuerzo de menú fijo, \$b 15; a la carta, \$b } 45 \\
11 \text { a.m. a } 9 \text { p.m. } \\
\text { Tienda de bocados (saltenas, hamburgucsas, salchichas) } \\
\text { con Ires cmpleados } \\
\text { Tienda de pasteles, pizzas, clc. } \\
\text { Local alquilado para fiestas } \\
\text { Pan y pasteles horneados en el local }\end{array}$ \\
\hline & II. Renta Neta \\
\hline
\end{tabular}

La descripción cs de un restaurante popular y de quinta clase (por los precios, ubicación, clientes y estilo)

Ventas brutas del restaurante $\mathbf{X X}$

(Cinco mozos x \$b 420,000)

Ventas brutas de otros servicios

Pastcles

\$b $2,100,000$

Fiestas

200,000

200,000

Ventas brutas totales

$2,500,000$

Gastos no contables (45\%)

$1,125,000$

Renta bruta

$1,375,000$

Gastos contables

Salarios

264,000

13\% Impuesto

113,000

Alquiler

42,000

Servicios públicos

48,000

Depreciación

50,000

Otro

100,000

617,000

Renta neta

758,000

\section{Impuesto}

Renta estimada sujeta al impuesto

$\$$ b 758,000

Impuesto

199,200

Renta sujeta al impuesto declarada en 1974

45,244

Impuesto pagado en 1974

13,573 


\section{Consideraciones administrativas}

Unidad para preparar los indicadores indirectos. Como se ha notado anteriormente, los indicadores indirectos de la renta son desarrollados por una unidad especial que hace una muestra de cada calegoría de negocio. La unidad debe ser separada del personal regular para facilitar la recolección de la información; a la vez, la unidad debe tener autorización legal para visitar y auditar los negocios. La meta ideal es preparar entre cinco y diez juegos de indicadores cada año. Se deben revisar los indicadores periódicamente —si es posible, cada año- para incorporar cambios de precios y de técnicas de producción.

Prioridades. Al escoger las actividades económicas para las que se preparan indicadores, la administración debe dar prioridad a esas actividades que (a) son claramente prósperas; $(b)$ numerosas; $(c)$ que requieren más de un indicador para calcular la renta, y $(d)$ que ofrecen un número razonable de fuentes de información.

Fuentes de información. Para formular los indicadores indirectos, se debe pedir la cooperación activa de las relevantes organizaciones de comercio. Para obtener su cooperación, se puede demostrar que si no se tributan todas las empresas, aparece la competencia desleal. Se deben usar tanto técnicas directas como indireclas para recoger la información sobre los costos y los precios. La información debe ser comparada con la información suministrada por vendedores al por mayor y por otras fuentes externas. Datos relevantes deben ser recogidos de las empresas que tienen la repulación de mantener registros confiables $y$ de declarar rentas razonables. Los oficiales reconocidos por la calidad de sus pruebas de declaraciones deben comprobar los datos.

Las estimaciones se deben basar en varios indicadores. Así se mejora la exactitud de las estimaciones y se evita que el contribuyente reduzca su impuesto al alterar la forma de llevar a cabo su negocio. Los mejores indicadores de las ventas brutas incluyen: (1) la cantidad de empleados; (2) el nivel de las habilidades de los empleados; (3) la maquinaria y el equipo instalado; (4) el nivel de los inventarios; (5) los materiales comprados, y (6) la información basada en otros impuestos.

Entrenamiento de los oficiales de tributación. Se deben ofrecer a los tasadores oficiales cursos cortos que expliquen la naturaleza y los objelivos de la tributación presuntiva y de su implementación en circunstancias diversas. Si tienen dificultades al aplicar un indicador particular, deben poder consultar con los individuos que lo diseñaron.

Publicación. Los indicadores de cada actividad económica deben ser publicados en forma de folleto para posibilitar la autotasación y así reducir el trabajo de la oficina de tributación. Este documento debe describir las características de la actividad y contener las tablas relevantes para estimar la renta. 


\section{El Selvador}

Tributación presuntiva. Casi no existe ninguna tributación de la renta presunta en la ley de El Salvador. La única excepción es el artículo 23 del Reglamento de la Ley de Impuesto sobre la Renta que permile asumir que el interés iguala "la diferencia entre la cantidad que reciba el deudor y la mayor cantidad que devuelva. Así mismo, se presume, salvo prueba de lo contrario, que lodo crédito devenga el interés legal..." (Orantes, p. 93).

Esta tributación presuntiva es inadecuada porque el interés forma sólo una parte de la renta global, y porque el interés es con frecuencia deducible. El Artículo 4, No. 5, de la Ley de Impuesto sobre la Renta incluye entre las rentas no gravables los intereses que "provengan directamente de los depósitos en ban$\cos y$ en asociaciones financieras, siempre que el sujeto pasivo beneficiado con estas rentas sea persona natural y además el titular de los depósilos". El Número $11 \mathrm{del}$ mismo artículo excluye "los intereses provenientes de créditos otorgados por instituciones financieras domiciliadas en el exterior, previamente calificadas estas instituciones por el Banco Central de Reserva de El Salvador". El Arlículo 29 , No. 10 de la misma ley excluye "los intereses generados por las cantidades tomadas en préstamo toda vez que sean invertidas en la fuente generadora de la renta gravable, así como los gastos incurridos en la constitución, renovación o cancelación de dichos préstamos" (Orantes, pp. 23, 35).

Aunque casi no existe ninguna tributación presuntiva sobre la renta, sí existe un método interesante de tribulación presuntiva sobre las ventas. El Artículo 152 de la Ley de Impuesto a La Transferencia de Bienes Muebles y a la Prestación de Servicios (IVA) declara que los oficiales pueden usar las diferencias entre las existencias de bienes que aparezcan en los registros y las que resulten de los inventarios comprobados para fijar el IVA sobre una empresa (Orantes, p. 20406). El oficial de tributación puede interpretar las faltantes del inventario como bienes transferidos cuyas ventas han sido omilidas de registrar en el año inmediato anterior. El oficial puede interpretar las sobrantes de inventario como evidencia del manejo de un negocio ocullo de los libros de contabilidad. En ambos casos, se puede presumir que las ventas actuales sean mayores que las ventas declaradas por la diferencia encontrada, y el IVA debido puede ser aumentado.

El mismo artículo permite que el oficial de tributación presuma, salvo prueba de lo contrario, que el resultado de promediar el total de las ventas en no menos de cinco días continuos o alternados de un mismo mes, multiplicado por el total de días hábiles comerciales del mismo, representan las ventas durante ese mes. Si el mencionado control se efectuara en no menos de cuatro meses altemos de un mismo año, el promedio mensual de venta se considerará suficientemente representalivo de las ventas y podrá, por lo tanto, aplicarse a los demás meses no controlados del mismo año. De los cuatro meses que se controlen, dos de ellos deberán corresponder al primer semestre del ejercicio y los otros dos al 
segundo. La diferencia de ventas entre las registradas y las estimadas presuntivamente determinará ventas o prestaciones de servicios gravados para este impuesto. Se presume que la misma diferencia se aplica al año anterior, y el tributo adicional no generará ningún crédito fiscal deducible.

Este sistema de tributación presuntiva tiene éxito en aumentar la recaudación de ingresos tributarios. También reduce la inequidad horizontal que surge cuando dos contribuyentes con las mismas ventas paguen impuestos distintos.

Sin embargo, el sistema sufre de varias debilidades. La primera es que se tributan las ventas solamente. El sistema no alcanza ni el impuesto sobre la renta de personas jurídicas, ni el de la renta personal. A fortiori, el sistema no mueve los difíciles de tributar al sistema regular de tributación de la renta. Por concentrarse exclusivamente en el IVA, el sistema tributario efectivo se hace más regresivo, y esto atrasa la satisfacción de las necesidades básicas que dan a la gente la oportunidad de participar en el proceso de desarrollo.

Una segunda debilidad es que el impuesto presuntivo salvadoreño no puede ser extendido a algunos grupos que son difíciles de tributar. No se pueden estimar las ventas de los agricultores al promediar las ventas de 5 días sobre 4 meses, porque hacen sus ventas principalmente después de sus cosechas. El impuesto tampoco anima a usar la tierra no cultivada o subutilizada porque no es un impuesto sobre la renta potencial de la tierra. Además, los profesionales fácilmente podrían ajustar sus cilas y sus precios para subestimar las ventas promedios y para evitar el impuesto.

Una tercera debilidad es que el impuesto corriente es costoso de aplicar. Los oficiales de tributación tienen que medir exactamente las ventas de cada negocio por cinco días en cuatro meses diferentes. Por ello, el costo de la administración rápidamente excede los ingresos adicionales cuando el tamaño de los negocios disminuye. También, debido al alto costo alto de la administración, no se pueden renovar los estimados con facilidad.

Tal vez la ventaja más importante del método salvadoreño es que da a los oficiales tributarios un conocimiento valioso de las ventas por cada tipo de negocio. Este conocimiento podría ser usado para efectuar el sistema tributario del modelo. El próximo paso sería usar este conocimiento para desarollar indicadores indirectos de las ventas y de la renta imponible. Si se hiciera esto, el Ministerio de Hacienda terminaría con más de una estimación de ventas que difícilmente se podría renovar. Se tendría un sistema que se podría extender a la renta de personas jurídicas y de personas naturales, que se podría extender a un rango mucho más amplio de negocios, que se podría revisar y llevaría a todo el mundo hacia la plena incorporación en el sistema regular de tributación sobre la renta.

Catastro de propiedades. Existe otro acontecimiento interesante que podría facilitar mucho la tributación presuntiva del sector agrícola. El Centro Nacional 
de Registro (CNR) está usando un sistema de medición satelital para registrar todas las propiedades del pais. Se pretende constatar linderos y establecer quiénes son los dueños reales de un millón ochocientas mil propiedades existentes para el año 2002. La constatación de medidas y propiedades se hace a la luz de la Ley Catastral.

Este catastro de propiedades podría servir como el primer paso para efectuar el impuesto presuntivo sobre la renta del sector agrícola. Después de establecer los linderos y la posesión, sólo faltará la determinación de la productividad de la tierra por región. Una entrevista con el subdireclor del Centro Nacional de Registro reveló que el mismo sisterna satelital sí tiene la capacidad de medir la fertilidad de la tierra (Velásquez). Una alternativa al uso del sistema satelital sería una muestra de la renta bruta y del costo de la producción por zona principal.

Progresividad. Desde 1989, la máxima tasa marginal del impuesto sobre la renta ha sido reducida drásticamente del 50 al 30 por ciento. Se podría argüir que la tasa máxima es demasiado baja. Se sabe que los supuestos incentivos de la reducida progresividad son bastante cuestionables (McGuire, pp. 647-51; Shome, Bird, 1992, p. 8). Es probable que el efecto principal de reducir la progresividad sea el atraso en la formación de un proceso inclusivo de desarrollo. Sin embargo, se podrán aumentar mucho los ingresos tributarios -y satisfacer mucho más necesidades básicas- por simplemente efectuar la tributación de la renta presunta usando el sisterna corriente de tasas.

Resistencia politica. Quizás, el obstáculo más grande a la tribulación presuntiva es la política. Para ejecutar la tributación presuntiva se exigen leyes. Claro, algunas personas de muchos recursos van a usar su influencia política para resistir la tributación progresiva de la renta presunta.

La reacción constructiva no es desesperar, sino buscar alianzas políticas. Las empresas más grandes están pagando el impuesto sobre la renta de personas jurídicas, mientras que sus competidores más pequeños no lo pagan. Del mismo modo, los trabajadores del sector formal están pagando el impuesto sobre la renta personal mientras que otros que ganan rentas similares no pagan nada. Además, grandes cantidades de personas de pocos recursos están pagando altos impuestos regresivos sobre las ventas precisamente porque las recaudaciones del impuesto sobre la renta están bajas. Parece que un partido político podría ganar apoyo general por incorporar la tributación de la renta presunta en su programa. 


\section{Otros países latinoafnericanos}

Hay un moviemiento general por toda Latinoamérica para tributar la renta presunta. Colombia introdujo un sistema de la tributación presuntiva en 1974 que ha tenido "mucho éxito"; y, en 1985, Bolivia reemplazó completamente su impuesto sobre la renta de personas jurídicas por un sistema presuntivo (Perry, Cap. 5). Durante la década de los ochenta, Brasil y Uruguay establecieron la tributación de la renta presunta (Pita, pp. 70-71, 163). En 1989, México introdujo el impuesto sobre la renta presunta que se describe abajo. Argentina y Perú han establecido un impuesto parecido al de México (De Marulanda 7). El Banco Inter-Americano de Desarrollo (IDB) informa que, desde 1991, la tributación sobre la renta presunta ha sido establecido en Ecuador, Guaternala y Honduras, y que en 1995 alguna forma de la tributación presuntiva ya existía en la mayoría de los países latinoamericanos (IDB, Progress, Cuadro 3.4, pp. 127-128). Shome pronostica que durante la década de los noventa, más países optarán por la tributación presuntiva (Shome).

Se dan muchas razones para este movimiento. Primero se dice que durante los años de la década de los ochenta, el impuesto sobre las ventas aumentó tanto que "están llegando en diversos países a una saturación, no respondiendo su recaudación en forma adecuada al incremento de sus bases o alícuotas" (Pita, p. 41). Segundo, las comparaciones con el sudeste de Asia, un modelo ejemplar de desarrollo, indica que la carga tributaria sobre la renta de Latinoamérica equivale solamente a la mitad de esa región (Pita, p. 42). Otros estudios indican que la carga tributaria de Latinoamérica - 14 por ciento- está baja comparada con la carga tanto de los países industrializados como de los países en vías de desarrollo. Sin embargo, la tributación del consumo está más o menos igual a la de las otras regiones. Es el impuesto sobre la renta que queda consistemente mucho más bajo (De Marulanda, 6). Tercero, se tiene siempre más evidencia que los supuestos incentivos para reducir la progresividad del impuesto sobre la renta no son eficaces (De Marulanda, p. 6). Cuarto, hay una preocupación creciente sobre la injusticia causada por las reformas tributarias de los ochenta, que han dejado los sistemas tributarios todavía más regresivos. Por fin, la mejor de todas las razones es que el recaudar fondos por el impuesto progresivo sobre la renta es la mejor manera de promover el desarrollo sostenido y equitativo.

\subsection{México}

México ilustra una forma de tributación presuntiva que se hace siempre más común y que el Banco Inter-Americano de Desarrollo recomienda para otros países latinoamericanos (BID 42). México impone un impuesto del 2 por ciento sobre los activos brutos de las empresas (Díaz, pp. 41-42). Esta tasa aproxima el impuesto sobre la renta de una empresa que tiene una ganancia del 5.7 por ciento sobre sus activos. La empresa recientemente establecida puede posponer 
el pago del impuesto, al igual que la empresa que tiene una historia de pago adecuado de sus impuestos, pero que experimenta fluctuaciones altas de sus ganancias o tiene períodos largos de maduración de sus inversiones.

El impuesto mexicano tiene varias ventajas. Su estructura es muy simple. Las recaudaciones del impuesto sobre la renta aumentaron al 12.9 por ciento en 1989 cuando fue introducido, aunque otras reformas del impuesto habrían causado una reducción de las recaudaciones. El impuesto es progresivo en cuanto que los dueños de las empresas son relativamente prósperos. El impuesto reduce la evasión y mejora la equidad horizontal por reducir las diferenciales tributarias entre las empresas de rentas iguales.

A pesar de sus ventajas, una comparación del impuesto con el modelo revela varias debilidades serias. Los activos son un solo indicador de la renta, y por esto se podría evitar el impuesto por reducir el valor de los activos. Los activos son difíciles de medir exactamente, lo cual podría causar evasión. La administración del sistema es de alto costo en el sentido de que es necesario medir los activos de todas las empresas, y esto lo hace difícil de renovar. La razón entre los activos y las utilidades puede variar sustancialmente entre las industrias, y entre las empresas de la misma industria, y así se pueden experimentar inequidades y pérdidas de ingresos. Precisamente por estas diferencias y por el costo administrativo relativo a los ingresos tribularios adicionales que se recauden, el impuesto probablemente sea restringido a las empresas grandes y medianas de manufaclura. Si es así, las empresas pequeñas, los profesionales y los agricultores no son tributados, y a fortiori no son movidos gradualmente al sistema regular de tributar la renta. Igualmente, las empresas medianas y grandes que ganan más del 5.7 por ciento sobre sus activos pagan insuficientemente y no son movidas al sistema regular de la tributación. El impuesto no tributa la renta personal. Si el impuesto fuera aplicado al sector agrícola, no se tomarían en cuenta las variaciones de la fertilidad de la tierra ni de la renta, y el impuesto no animaría el uso mejor de la tierra por tributar la renta potencial. Claro, el impuesto mexicano es un sustituto sumamente deficiente del impuesto recomendado por el modelo Musgrave.

\section{Política}

El Banco Mundial estima que en 1995, el 22 por ciento de los niños salvadoreños menores de cinco años estaban malnutridos, sólo el 73 por ciento de la población tenía acceso a servicios sanitarios, y el 62 por ciento tenía acceso al agua potable, y la tasa de analfabetismo entre adultos era del 29 por ciento (World Bank, Cuadro 1, p. 214, y Cuadro 6, p. 224).

Estas estadísticas indican que grandes cantidades de gente están excluidas del proceso de desarrollo y de sus beneficios, y que el desafio más grande que 
enfrenta El Salvador es dar a soda la gente la oportunidad de participar en un proceso de desarrollo sostenido y equitativo. Para cumplir con este desafío, es necesario usar la tributación progresiva para recaudar los fondos necesarios y usarlos para satisfacer las necesidades básicas que forman una fuerza de trabajo productiva.

La tributación de la renta presunta es la única manera faclible de cumplir con este objetivo importante. El renombrado economista Richard Bird escribió que la tributación de la renta presunta "es la única manera de expandir el uso del sistema de tributación directa", y que tal tributación "conduce a un mejoramiento significativo de la equidad y de la eficiencia del sistema tribulario en la mayoría de los países en vías de desarrollo" (Bird, 1990, p. 113). En otro lugar escribio que la clave para el uso exitoso del impuesto sobre la renta es "sin excepción un sistema bueno de retención suplido por algún tipo de tributación presuntiva sobre los grupos difíciles de tributar que está basada en la ley" (Bird, 1992 , p. 213). Este trabajo ha bosquejado el sistema excelente de Richard Musgrave para efectuar la tributación de la renta presunta e introducir gradualmente a todos los contribuyentes a la participación plena en el sistema regular de la tributación sobre la renta. Así como Musgrave adaptó el sistema israelí para servir las circunstancias de Bolivia, los salvadoreños deben sentirse libres para adaptar el sistema para servir bien las circunstancias de El Salvador. Sin embargo, es necesario que esta adaptación incluya varios pasos.

Primero, la filosofía predominante de la tributación debe scr alterada. La tendencia ha sido la de enfatizar el impuesto regresivo sobre las ventas (IVA) más que el impuesto progresivo sobre la renta. Es necesario reconocer el impacto destructivo de la tributación regresiva sobre el desarrollo, y volver la atención una vez más hacia el "mejor de lodos los impuestos", el impuesto progresivo sobre la renta.

Segundo, será necesario aunar el apoyo político para crear las leyes que legalicen el diseño y la realización de la tributación de la renta presunta. Los aliados potenciales incluyen las empresas y los ciudadanos que ya pagan el impuesto sobre la renta, y la gente de pocos recursos que son tributados regresivamente.

Tercero, hay que comenzar el trabajo técnico asociado con la realización del sistema. Hay que crear una unidad especial dentro del Ministerio de Hacienda. Esta unidad tiene que diseñar el sistema en cooperación con otros salvadoreños, hacer unas muestras y elaborar cuadros como las de este trabajo. Hay que ordenar que el CNR conduzca una medición de la productividad de la tierra por región. En fin, se necesita una campaña para hacer efectivo el sistema nuevo.

Cuarto, se necesilan nuevas prioridades presupuestarias que dediquen fondos suficientes para satisfacer las necesidades básicas dentro de un período limitado. 
Richard Bird dice que la principal alternativa factible a la tribulación presuntiva es no hacer nada, o explícitamente (por fijar un nivel alto de exención, por ejemplo), o mucho peor - $\mathrm{y}$ mucho más común- implícitamente por no cumplir la ley (Bird, 1992, p. 110). El no hacer nada dejaría al país, de manera indefinida, en un proceso de desarrollo desequilibrado que excluiría a mucha gente sin ser culpa suya. La tributación de la renta presunta es un paso tanto factible como necesario para cumplir con el desafío más grande que enfrenta El Salvador, el desarrollo sostenido y equitativo.

\section{Bibliografia}

Banco Central de Reserva de El Salvador, datos suministrados por el Departamento de Finanzas Públicas, 5 de junio, 1997.

Banco Central de Reserva, Revista Trimestral, encro-febrero-marzo, 1997.

Banco Interamericano de Desarrollo, "La Tributación en América Latina: logros y perspectivas", Seminario patrocinado por el Banco Interamericano de Desarrollo, Washington, D.C., 26-27 de julio, 1993.

Bird, Richard M., Tax Policy \& Economic Development, Baltimore: The Johns Hopkins University Press, 1992.

Bird, Richard M. y Oldman, Oliver (eds.), Taxation in Developing Countries, 4ta cdición, The Johns Hopkins University Press, 1990.

De Marulanda, Nohra Rey, "Taxation in Latin Amcrica and the Caribbean: Achievements and Outlook", en Reform of Tax Administration in Latin America: Progress and Perspectives, Washington D.C.: Intcr-American Development Bank, 1993, pp. 1-16.

Díaz, Francisco Gil, "Fiscal Policy and Tax Administration: The Experience of Mexico", en Inter-American Development Bank, Rejorm of Tax Administration in Latin America: Seminar sponsored by the Inter-American Development Bank, Washinglon, D.C., 2627 de julio, 1993, pp. 39-58.

Inter-American Development Bank, Economic and Social Progress in Latin America: 1996 Report, Distributed by the Johns Hopkins Universily Press for the Inter-American Development Bank, Washington, D.C.: noviembre, 1996.

Inter-Amcrican Development Bank, Reform of Tax Administration in Latin America: Progress and Perspectives, Washington, D.C.: Inter-American Development Bank, julio, 1993.

MeClure, Charles E. Jr., "Net Wealth and Presumptive Taxation in Colombia", en Richard M. Bird y Oliver Oldman (eds.), Taxotion in Developing Countries, 4ta edic., Baltimore: The Johns Hopkins University Press, 1990, pp. 288-95.

McGuire, J. Michael, "Los cambios de la estructura tributaria de El Salvador: implicaciones para cl desarrollo", Realidad Económico-social, Año III, No. 18, noviembre-dicicmbre, 1990, pp. 641-676.

Musgrave, Richard, A., "Income Taxation of Hard to Tax Groups", en Richard M. Bird y Oliver Oldman (eds.), Taxation in Developing Countries, 4ta edic., Ballimore: The Johns Hopkins Universily Press, 1990, pp. 299-309.

Musgrave, Richard A., Fiscal Reform in Bolivia, Cambridge, Mass: Harvard Law School International Tax Program, 1981.

National Trade Data Bank, El Salvador, http://www.stat-usa.gov. 
Orantes, Ricardo Mendoza, ed., Recopilación de Leyes Tributarias 1997, San Salvador: Editorial Jurídica Salvadoreña, marzo, 1997.

Perry, Guillermo y Herrera, Ana María, Public Finances, Stabilization and Structural Reform in Latin America, Washinglon, D.C.: Inter-American Development Bank, 1994.

Pila, Claudino, La reforma tributaria en América Latina en la década de los años 80: Efectos de suficiencia, equidad, neutralidad y simplificación, Washington, D.C.: InterAmerican Development Bank, Seric de Documentos de Trabajo 164, 1993.

Shome, Parthasarathi, "Trends and Future Directions in Tax Policy Reform: A Latin American Perspective", IMF Working Paper WP/92/43, junio, 1992.

Tanzi, Vito, "Tax Rcform in Latin Amcrica in the Past Decade", en Inter-American Development Bank, Reform of Tax Administration in Latin America, Washington, D.C.: Inter-American Development Bank, 1966.

Tóchez, Irving Pabcl, Director General de Impuestos Internos, El Salvador, entrevista, 17 de junio de 1997.

Velásquez, Laurence Angel, Subdirector Ejecutivo, Centro Nacional de Registro, entrevista, 4 de julio de 1997.

World Bank, World Development Report 1997, New York: Oxford University Press, junio, 1997.

\section{Nota}

1. Desgraciadamente, Musgrave no da una definición clara del término "gastos no contables". Si parece que tales gastos no existen, se puede ignorar el concepto. 